\title{
A rolling regression analysis of international transmission of inflation in Malaysia
}

\begin{abstract}
The paper assesses the transmission of foreign inflationary disturbances for Malaysia. Using quarterly data from 1971 to 2003, we form a four-variable vector error correction model (VECM) consisting of domestic prices, US prices, Ringgit exchange rate and relative interest rate. Apart from the full-sample analysis, recursive and rolling regressions are adopted to examine potential changes in inflation transmission from the US to Malaysia. As a basis for inferences, we rely on the speed of adjustments estimates as well as the sig-nificance of lagged first-differenced terms of the VECM. The results unequivocally suggest significant spillover of US inflationary disturbances to Malaysia in the short run regardless of the estimation periods. However, the speed of adjustment estimates for domestic prices tend to decline or turn insignificant when recent observations are added. Our findings demonstrate that inflation transmission across nations ought not to be cast in the light of exchange rate regimes alone. Indeed, the degree of capital mobility may have played a more dominant role.
\end{abstract}

Keyword: Inflation transmission; Malaysia; Rolling regressions; VEC 